\title{
Deterioration of medieval painting in the chapel of the Holy Nail, Siena (Italy) partially treated with Paraloid B72
}

\author{
Claudio Milanesi ${ }^{\mathrm{a}, *}$, Franco Baldi ${ }^{\mathrm{b}}$, Sara Borin ${ }^{\mathrm{c}}$, Lorenzo Brusetti ${ }^{\mathrm{d}}$, Fabrizio Ciampolini ${ }^{\mathrm{a}}$, \\ Fabrizio Iacopini ${ }^{\mathrm{e}}$, Mauro Cresti ${ }^{\mathrm{a}}$ \\ ${ }^{a}$ Department of Environmental Science G. Sarfatti, University of Siena, Via Mattioli 4, 53100 Siena, Italy \\ ${ }^{\mathrm{b}}$ Department of Environmental Science, Cà Foscari University of Venezia, Calle Larga S. Marta, 30121 Venice, Italy \\ ${ }^{c}$ Department of Food Science and Technology, University of Milan, Via Celoria 2, 20133 Milan, Italy \\ ${ }^{\mathrm{d}}$ Faculty of Science and Technology, Free University of Bolzano/Bozen, Via Sernesi 1, 39100 Bolzano/Bozen, Italy \\ e A.T.I., Via Ciurini 6, Castelfiorentino, Florence, Italy
}

\section{A R T I C L E I N F O}

\section{Article history:}

Received 30 December 2008

Received in revised form

10 March 2009

Accepted 10 March 2009

Available online 28 April 2009

\section{Keywords:}

16S rRNA clone libraries

Deterioration

Element analysis

Firmicutes

Medieval painting

\begin{abstract}
A B S T R A C T
Painted surfaces in the Chapel of the Holy Nail in the medieval ex-hospital of Siena show five areas of oxidation and blackening. Most were treated with Paraloid B72 acrylic resin 40 years ago. To study deterioration of the painted surfaces by scanning microscopy with X-ray dispersion microanalysis, fragments obtained from the five areas were analyzed directly and after hydration. Hydrated fragments treated with Paraloid showed a compact, shiny, impermeable surface. The acrylic resin forms a layer that inhibits interaction of the painting with the environment, including transpiration and gaseous exchange. Element composition of paint layers of different colours revealed gold, iron (oxides in ochre) and lead (oxide) tempered with lime and/or gypsum. A few microbial cells were found on all fragments. To study biological deterioration in the five areas, fragments were hydrated and incubated in minimal culture medium without added carbon source to select bacteria capable of using carbon sources in the medieval fresco. Analysis did not reveal any spores or hyphae, and excluded physical and mechanical damage. Bacteria of the genus Bacillus were isolated only from untreated samples. Paraloid resin forms an inert film over the mural, preventing access to microbes able to use nutrient sources in the painted layer. The screening of $16 \mathrm{~S}$ rRNA libraries from enrichment cultures showed wide phylogenetic diversity. Forty-four percent of the clones retrieved from the clone library were affiliated with the order Firmicutes, confirming the prevalence of aerobic spore-formers among the colonizing microflora. Firmicutes therefore presumably produced extracellular material which made water available to other bacteria which may have converted thiosulphate in the medieval tempera to sulphur globules. Sulphur is a known oxidant of metallic pigments, in this case aluminium, which may explain the blackening of the untreated sample.

(c) 2009 Elsevier Ltd. All rights reserved.
\end{abstract}

\section{Introduction}

Deterioration of paintings is a multidisciplinary field involving the arts, humanities and science. The best strategy for studying deterioration of artistic materials induced by environmental agents and their restoration calls for detailed knowledge of the materials originally employed by the artist. In medieval paintings, inorganic pigments, mainly minerals, were tempered with organic and/or inorganic materials. The oldest handbook of pictorial technique, "Libro dell'Arte" by Cennino Cennini (Cennini, 1437), is still

\footnotetext{
* Corresponding author. Tel.: +39 577 232895; fax: +39 57723286.

E-mail address: milanesi@unisi.it (C. Milanesi).
}

a precious source of information about pigment composition for interpreting element compositions of ancient painted surfaces obtained by scanning electron microscopy (SEM-EDX) microanalysis. The colours used by medieval Italian artists were often made with pigments containing high concentrations of heavy metals such as arsenic, lead, copper or mercury (Ciferri, 1999), that can be identified and quantified by SEM-EDX microanalysis.

Characterization of the whole complex of tempera constituents used in medieval painting is nevertheless difficult. Medieval tempera was a mixture of inorganic pigments and natural organic adhesive substances, such as egg yolk rich in proteins and fatty acids (Huang et al., 2003; Hosamani and Pattanashettar, 2003), fig latex which contains triterpenoids (Saeed and Sabir, 2002), animal fat (Ciferri, 1999) and other compounds, depending on the type of colour and the artist's experience. 
Dampness of walls causes efflorescences and is probably the main factor promoting chemical, physical and biological deterioration. The organic component of painting tempera can promote in situ microbial activity (Ciferri, 1999) providing carbon and energy sources for aerobic heterotrophic bacteria. Heavy metals in the organic fraction of tempera help preserve the painted surface, since their toxicity inhibits the growth of many microorganisms. Mechanisms of heavy metal resistance and detoxification are, however, known among bacterial species (Silver and Phung, 2005; Achour et al., 2007).

The natural porosity of frescoes makes their surfaces receptive to microbial spores and vegetative cells transported by airborne particulate, found in greater quantities near windows, doors and floors (Saarela et al., 2004). Environmental parameters such as humidity, poor ventilation and hot illumination facilitate the growth of microbes that use tempera constituents as nutrients, promoting biofilms composed of cells and viscous extracellular polymeric substances (EPS) involved in the chemical and physical degradation of paintings (Milanesi et al., 2006b; Grassi et al., 2007). The chemical degradation occurring with biological attack is due to physical corrosion (Warscheid and Braams, 2000; Beech, 2004), oxidation of metal ions, and pigment changes (Urzì and Realini, 1998).

The chapel of the Holy Nail, decorated with frescoes representing scenes from the Old and New Testaments by Lorenzo di Pietro, alias 'Il Vecchietta' (1446-1449), is in a building known as Santa Maria della Scala which was one of the first hospitals in Europe. Founded between the 10th and 11th centuries, it provided shelter for orphans and pilgrims on the Francigena route from Canterbury to Rome.

Prompted by the Florence flood of 1966 that damaged the artistic treasures of that city, the Istituto Centrale del Restauro in Rome recommended that acrylic resins such as Paraloid B 72 be used against fungal and bacterial contamination (Bassi and Giacobini, 2001; Kiwaga et al., 2005). Some parts of the Holy Nail chapel, including the wooden canopy above the altar, showed blackening and oxidation and in the 1970s were treated with Paraloid B 72 acrylic resin.

Paraloid is soluble in acetone or ethanol and solidifies to form a film and fixative. It has been shown to alter the physicochemical interface between murals and the environment. The treated frescoes showed a shiny yellowish surface, subject to the so-called caramel effect (Milanesi et al., 2006a; Grassi et al., 2007). Impregnation of the painted surface by the polymer modified the morphology of the porous matrix, decreasing vapour permeability (Carretti and Dei, 2004). Modification of surface hydrophilicity may also limit absorption of moulds and other microorganisms: the polymer molecules introduce repulsive interactions between the surface and potential adhering species (Glass, 1997; Walton et al., 1997). Only fungi have been found to grow on acrylic-treated surfaces and their degrading activity was presumably due to physical disruption of the Paraloid film (Cappitelli et al., 2007b; Cappitelli and Sorlini, 2008).

The aim of this study was to determine possible causes of chemical and/or biological deterioration of the original painted surfaces in the chapel. Paraloid-treated and untreated samples of deteriorated painted surfaces were studied by scanning electron microscopy and the microbial communities colonizing the surfaces were analyzed.

\section{Materials and methods}

\subsection{Sampling of painted fragments}

The chapel of the Holy Nail in what is now Santa Maria della Scala Museum, Siena (Italy), has been described by Milanesi et al. (2006a), and Grassi et al. (2007). Restoration of the medieval frescoes provided a good opportunity to detach very small fragments from the painted surface. Minimal specimens of wall surface (approximately $1 \times 3 \mathrm{~mm}, 0.5 \mathrm{~mm}$ thick) were detached with sterile tweezers from four visibly deteriorated fresco areas and from the canopy wood above the altar (Fig. 1, gray circles) and placed in sterile plastic tubes.

\subsection{Scanning microscope observations and microanalysis}

The Paraloid B72 acrylic plastic resin was analyzed for element composition to establish its contribution to the pictorial surface. Immediately after detachment, some fragments were glued to standard vacuum-clean stubs and coated with graphite (Edwards, carbon scancoat, S150A). Other fragments from each area were hydrated by incubation in a humidity chamber for $18 \mathrm{~h}$, and then glued in the same way as dry samples. Rehydration of specimens revitalizes fungal spores and other microbial structures so that they can be recognized (Milanesi et al., 2006a). All specimens were observed by scanning electron microscopy (SEM-EDX) (Philips XL20). The instrument was equipped with an EDAX DX4 probe for energy-dispersive X-ray microanalysis used at an acceleration voltage of $20 \mathrm{kV}$ to determine the characteristics of the painted surface. Concentrations had an approximate error of $1 \%$. Mean concentrations and standard deviations of each element were calculated from five random determinations on different spots of each sample. The X-ray beam was $4 \mu \mathrm{m}$ wide and penetrated to a depth of $2 \mu \mathrm{m}$.

\subsection{Isolation of aerobic heterotrophic bacteria}

Enrichment cultures in minimal medium without any other carbon source were prepared with the fragments and incubated for 15 days at $28{ }^{\circ} \mathrm{C}$. The medium contained per litre: $1 \mathrm{~g} \mathrm{MgSO}_{4} \cdot 7 \mathrm{H}_{2} \mathrm{O}$, $0.7 \mathrm{~g} \mathrm{KCl}, 2 \mathrm{~g} \mathrm{KH}_{2} \mathrm{PO}_{4}, 3 \mathrm{~g} \mathrm{Na}_{2} \mathrm{HPO}_{4}, 1 \mathrm{~g} \mathrm{NH}_{4} \mathrm{NO}_{3}, \mathrm{pH}$ 6.7. From positive enrichments, bacterial isolates were obtained and identified, as previously described (Milanesi et al., 2006b).

\subsection{Total DNA extraction and bacterial 16S rRNA gene cloning library}

16S rRNA gene sequences were submitted to the EMBL database under accession numbers from FM211909 to FM212007.

Total DNA was extracted and purified from Paraloid-treated and untreated fragments. Hydrated fragments and others cultured as previously described (Milanesi et al., 2006b) were processed using FastDNA SPIN Kit for Soil (BIO 101 Systems Q-BIO gene).

Almost complete bacterial 16S rRNA genes were amplified from extracted DNA using universal primers for bacteria $27 \mathrm{~F}$ and $1440 \mathrm{R}$ as previously detailed (Brusetti et al., 2008). The amplicons were purified, ligated in pGEM vector and cloned in JM300 competent E. coli cells. Positive clones were screened by PCR for inserts using universal primers T7 and U19 and about 800 bp were sequenced with 27F primer. Putative chimeric sequences were evaluated using the Chimera Detection Program in the SimRank 2.7 package available through the Ribosomal Database Project (RDP) (Cole et al., 2003). Generated sequences were first compared to sequences obtained from RDP II (Classifier: Naive Bayesian rRNA Classifier Version 1.0) and then compared to GenBank sequences using BLASTN (Altschul et al., 1997). Nucleotide sequences were multialigned with ClustalX v.1.83 (Thompson et al., 1997). Alignments were checked manually and poorly aligned or divergent regions were eliminated using GBlocks v.0.91b (Castresana, 2000) with a minimum block of five and allowed gap positions equal to half. Operational taxonomic units (OTUs) were defined at 97\% similarity 

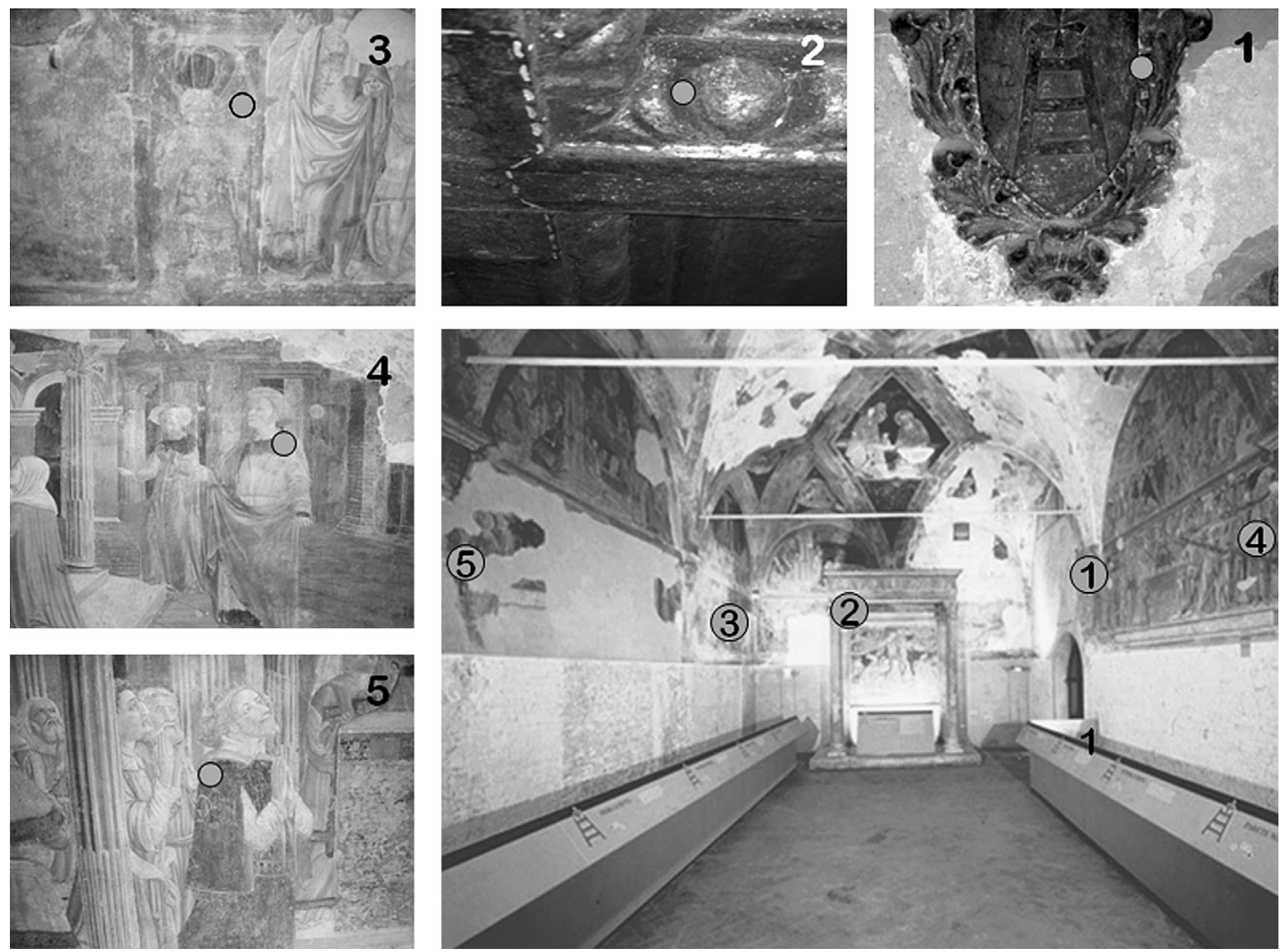

Fig. 1. Painting in the medieval chapel of the Holy Nail, Siena, showing sampling of fragments from damaged areas (numbered and circled).

by DNA_DIST software of the PHYLIP package. Phylogenetic analysis was performed using the neighbour-joining method with the Kimura2-parameter correction model in the software MEGA (v. 4.0) (Tamura et al., 2007). Statistical significance of branching was verified by bootstrapping (Felsenstein, 1985), involving construction and analysis of 1000 trees from the data set in the software MEGA. Rarefaction analysis and diversity indices for each library were obtained using PAST 1.19 software from the website http:// folk.uio.no/ohammer/past/.

\section{Results and discussion}

\subsection{Scanning electron microscopy and microanalysis}

SEM-EDX microanalysis for chemical degradation did not reveal significant differences between dry and hydrated specimens from the five damaged areas. Analysis of a hydrated Paraloid-treated fragment (Fig. 2) showed a compact surface. In contrast, dry and hydrated fragments of the sample without Paraloid treatment (from the third area) showed porous surface morphology. The percentage composition of elements is shown in Fig. 3.

The first study area (Fig. 1.1) was heraldry on stone (basalt) with gold leaf treated with Paraloid. SEM-EDX analysis (Fig. 3) confirmed the presence of gold (58\%). The low C:O ratio (1.2) and the presence of Ca confirmed that lime $(\mathrm{CaO})$ had been applied to the stone. Once the thin gold lamina was destroyed, blackened basalt was revealed. SEM micrographs of dry fragments (Fig. 2.1a) showed cracks on the smooth surface and deposited material. Hydrated fragments (Fig. 2.1b) showed a cracked surface with less deposition, indicating that salts had dissolved in water.

The second study area was on the wooden altar canopy (Fig. 1.2), probably Quercus ilex or robur, Castanea sp., Juglans regia or Buxus sempervirens, also treated with Paraloid. SEM-EDX analysis (Fig. 3) confirmed the presence of gold (17.8\%) but since the substrate was elastic (wood), the element was probably mixed into the tempera with ochre (iron oxides) and lime, as confirmed by the presence of iron (11.8\%) and Ca (4.03\%). The low C:O ratio (2.94) confirmed the presence of metal oxides on the surface. SEM micrographs of the surface were similar to those of the first area, with cracked resin and deposited material (Fig. 2.2a). The hydrated fragment (Fig. 2.2b) had a smoother surface where cracks were more evident, probably because much deposited material was water-soluble. In this case, the blackening was caused by the effect of moisture on iron oxides in tempera containing ochre.

The third study area, a pictorial fresco not treated with Paraloid, was the most damaged (Fig. 1.3). Fragments had a porous surface. SEM-EDX analysis (Fig. 3) showed high concentrations of $\mathrm{Ca}$ (23.6\%), S (11.05\%) and O (49.3\%), typical of gypsum rendering $\left(\mathrm{CaSO}_{4}\right)$, indicating that the fresco may have lost its inorganic pigment through deterioration. Metal residues ( $\mathrm{Al}, \mathrm{Si}, \mathrm{Mg}$ and $\mathrm{Na}$ ) at concentrations $<1 \%$ were detected. The $\mathrm{C}$ : $\mathrm{O}$ ratio was the lowest in all samples (0.28), confirming that oxides were prevalent and that Paraloid resin was absent. SEM micrographs of the surface showed high porosity with deposited materials in the form of micro 

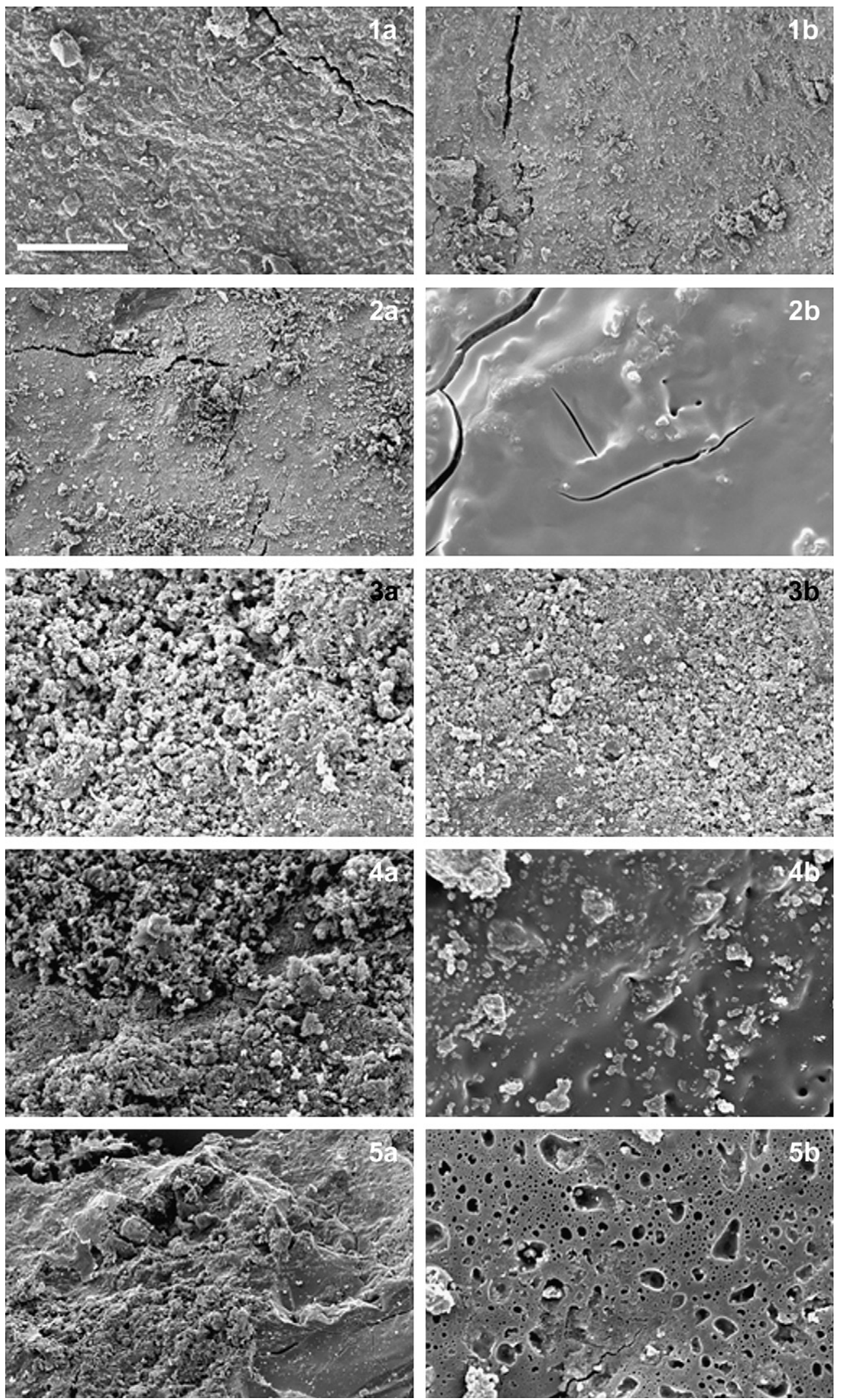

Fig. 2. Scanning electron micrograph showing dry (a) and hydrated (b) fragments of painted surface. Bar $=50 \mu \mathrm{m}$. 


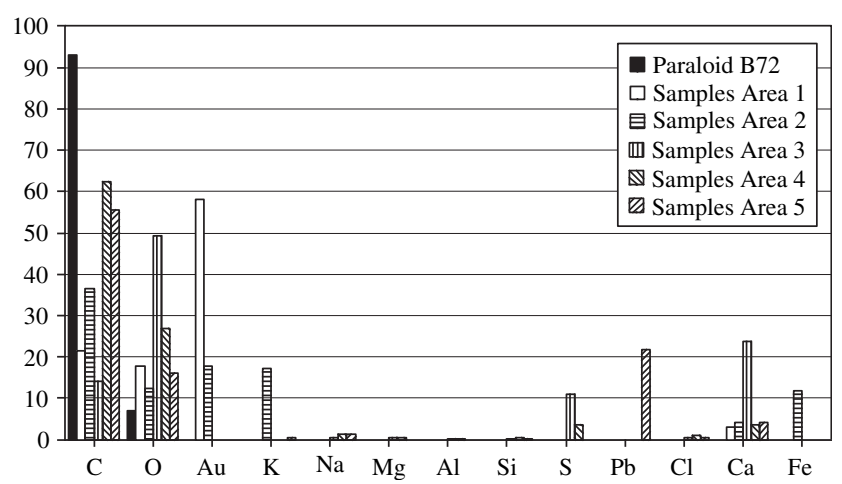

Fig. 3. Microanalysis of elements in painting fragments by scanning microscopy with energy-dispersive X-ray system.

spheres and micro holes (Fig. 2.3a). The hydrated fragment still showed high porosity but less than the dry specimen (Fig. 2.3b). These samples contained aluminium that is oxidized by sulphur.

The fourth study area was fresco treated with Paraloid (Fig. 1.4). SEM-EDX analysis (Fig. 3) showed the highest concentration of $\mathrm{C}$ $(62.3 \%)$ indicating that the resin was thicker on this fragment. The C:O ratio was 2.3 and the co-presence of Ca (3.5\%) and S (3.62\%) indicated the presence of oxygen-rich salt such as gypsum. Traces of $\mathrm{Al}, \mathrm{Na}, \mathrm{Si}$ and $\mathrm{Mg}$ were presumably residues of an inorganic pigment. The similar concentrations of $\mathrm{Na}$ and $\mathrm{Cl}(>1 \%)$ suggested the presence of salt efflorescence on the surface. This was in line with the difference between dry (Fig. 2.4a) and hydrated (Fig. 2.4b) specimens: the former showed deposited material, whereas the latter had a smoother surface with fewer deposits. These samples also contained aluminium that is oxidized by salt.

The fifth study area was more colourful fresco treated with Paraloid resin (Fig. 1.5). SEM-EDX analysis (Fig. 3) showed a high concentration of $\mathrm{C}(55.5 \%)$. The C:O ratio of 3.46 indicated a high concentration of oxides, characterised in this case by $\mathrm{Pb}(21.7 \%)$ and $\mathrm{Ca}(4.1 \%)$, under the resin. The presence of lead is consistent with widespread medieval use of minium $\left(\mathrm{Pb}_{3} \mathrm{O}_{4}\right)$ as red and orange pigment (Cennini, 1437). The dry fragment (Fig. 2.5a) showed much deposited material, unlike the hydrated sample (Fig. 2.5b), the surface of which showed many small holes of different sizes and shapes.

Dry and hydrated Paraloid-treated and untreated samples observed by SEM at high magnifications showed potential deteriogen species on the surface in quiescent state. Determination of these species was attempted as follows.

\subsection{Microbiological study}

To select deteriogens capable of colonizing the medieval fresco surface, some of the painting fragments were hydrated while others were inoculated in minimal mineral medium without any added carbon source. Microscopy failed to reveal growth of hyphae after $48 \mathrm{~h}$, though Cladosporium sp. and other melanin-producing fungi are known to grow on dry acrylic resin surfaces (Cappitelli et al., 2007a,b). To identify bacteria adhering to the surface, we attempted to extract total DNA directly from fragments by 16S rRNA gene cloning, but we did not obtain a sufficient amount of DNA from any of them, with the Paraloid treatment. Probably the size of the samples may have been too small to extract a sufficient amount of DNA. Microbial growth was obtained from fragments of the third study area, not treated with Paraloid. This showed that Paraloid effectively protected the surface of the frescoes. The copolymer of ethylmethacrylate is inert, nonnutrient and resistant to bacterial attack (Cappitelli and Sorlini, 2008). Quiescent microbiota inhabiting the fragment surface did not proliferate on surfaces protected by Paraloid. Culture selected cultivable microflora able to use natural organic substances in the medieval fresco as nutrient.

The microbial population hydrated, were able to grow in medium that has been enriched with organic substances extracted from medieval fresco.

In hydrated fragments two strains were isolated and identified as uncultured Bacillus sp. and Brevibacillus ruber. These genera belong to the order Firmicutes, which consists of Gram positive aerobic spore-formers, typical components of airborne microflora, readily transported from site to site and able to colonize surfaces with minimum humidity and nutrients (Fang et al., 2007; El-Banna and Quddoumi, 2007).

Since the vast majority of environmental microbial strains cannot be cultured (Amann et al., 1995) we analyzed bacterial diversity in detail in enrichment cultures grown from the fresco areas. Screening of 95 clones of a 16S rRNA gene library built from the metagenome of the enrichment led to identification of 32 Operational Taxonomic Units (OTU, grouping sequences with 97\% similarity) from the untreated fresco surface. Rarefaction analysis of the clone library indicated that we explored $72.2 \%$ of the theoretical total number of bacterial taxa present, with a standard deviation of about 3\%. The identification of clones at phylum level indicated wider phylogenetic diversity than emerged from the culture-based approach (Fig. 4). However, Firmicutes turned out to be the dominant phylogenetic group, accounting for $44 \%$ of the clones. We therefore suggest that Firmicutes bacteria in the fresco converted thiosulphate to the sulphur globules (Jørgensen, 1990), which we detected by microanalysis. This finding, together with isolation of Bacillus and Brevibacillus strains able to grow using air or frescoassociated organic matter as carbon source, suggests that the biodegradative microflora included Bacillus. Further investigations are needed to demonstrate the capacity of these isolates to induce biodeterioration, and to determine environmental conditions that inhibit their growth, in order to establish an appropriate biorestoration policy.

Proteobacteria were the second most abundant group, accounting for $42 \%$ of the clones. They comprised members of the alpha (17\%), beta (17\%) and gamma (8\%) subgroups which include aerobic environmental bacteria with various metabolisms and versatile degradation capacities. The clone libraries also revealed important families and genera of air, soil and medical environments: Actinobacteria, Bacteroidetes, Fusobacteria, Kocuria, Burkholderiales, Streptococcus, Neisseriaceae, Moraxella and Corynebacterium. Actinobacteria, especially Kocuria species, were previously shown to be components of the fresco microflora and to tolerate high $\mathrm{NaCl}$ concentrations (Milanesi et al., 2006b), while members of the phylogenetic groups Neisseriaceae, Burkholderiales and Streptococcus are well recognized pathogens. Interestingly, nucleotide-nucleotide homology showed that many of the clones found had close relatives among human-associated bacteria isolated from houses, urban settings and hospitals. Sixty-five percent of the clones were very similar to bacterial isolates or clones from clinical specimens, including agents of infection and disease (19\%).

\section{Conclusions}

The polymer was found to protect and fix the painting surface but reduced permeability of the supports to vapours, altering the physicochemical behaviour of the interface between the mural and the environment, as shown by analysis of dry and hydrated fragments. Only one surface out of the five analyzed was not treated with Paraloid resin. Humidity combined with different chemical compounds accelerated chemical oxidation and blackening in the 


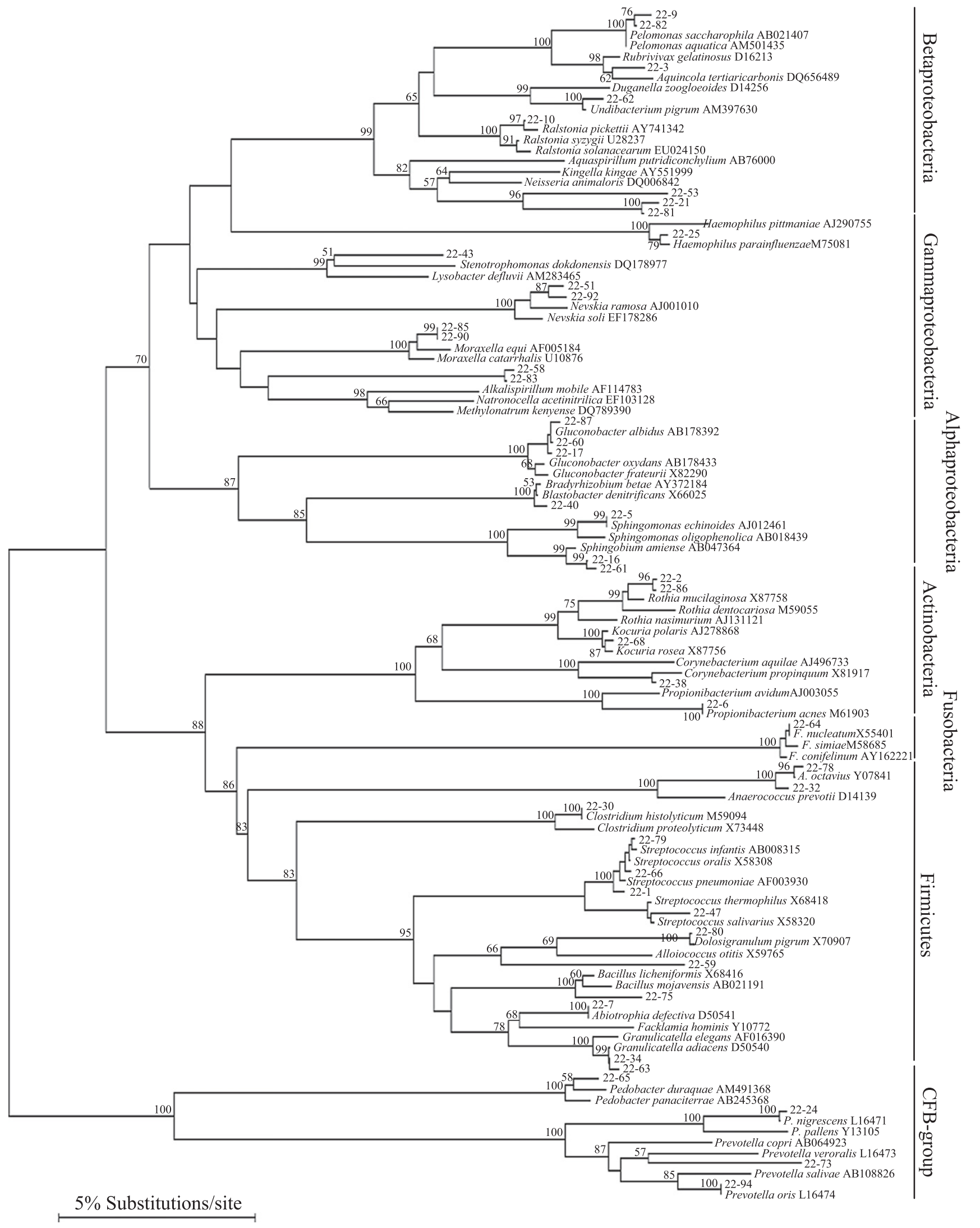

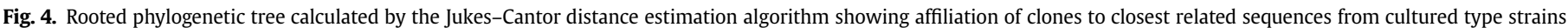
belonging to different bacterial divisions. Percentages of 1000 bootstrap resamplings supporting the branching orders of each analysis are only shown for values over $50 \%$. 
different damaged areas. Paraloid-treated and untreated samples observed by SEM at high magnifications showed potential deteriogen species in quiescent state and 16S rRNA extraction revealed few microbial cells. Bacteria were only found on untreated specimens. The size of the samples was too small to extract a sufficient amount of DNA, making it impossible to analyze the microbiota inhabiting the fragments.

Most bacteria determined in this study were pathogenic and compatible with the habitat, that was a hospital from the 13th century until a few years ago. Other bacteria were detected but not considered capable of damaging the painting. The method adopted may have selected bacteria able to use organic carbon sources in the medieval frescoes. Bacterial diversity was elevated with a predominance of Firmicutes that metabolize thiosulphate. We hypothesised that pioneer bacteria attach to the pictorial surface by producing extracellular material, which retains water and provides a carbon source available to other bacteria.

\section{Acknowledgements}

The authors thank Dr. Enrico Toti, Conservator of the Museum complex Santa Maria della Scala, Siena, for his encouragement and for helping obtain small fragments from the painted surfaces.

\section{References}

Achour, R.A., Bauda, P., Billard, P., 2007. Diversity of arsenite transporter genes from arsenic-resistant soil bacteria. Research in Microbiology 158, 128-137.

Altschul, S.F., Madden, T.L., Schaffer, A.A., Zhang, J., Zhang, Z., Miller, W., Lipman, D.J., 1997. Gapped BLAST and PSI-BLAST: a new generation of protein database search programs. Nucleic Acids Research 25, 3389-3402.

Amann, R.I., Ludwig, W., Schleifer, K.H., 1995. Phylogenetic identification and in situ detection of individual microbial cells without cultivation. Microbiology Review 59, 143-169.

Bassi, M., Giacobini, C., 2001. Scanning electron microscopy a new technique in the study of the microbiology of works of art. International Biodeterioration \& Biodegradation 48 (1-4), 55-66.

Beech, I.B., 2004. Corrosion of technical materials in the presence of biofilms current understanding and state of the art methods of study. International Biodeterioration \& Biodegradation 53, 177-183.

Brusetti, L., Glad, T., Borin, S., Myren, P., Rizzi, A., Johnsen, P.J., Carter, P., Daffonchio, D., Nielsen, K.M., 2008. Low prevalence of blaTEM genes in Arctic environments and agricultural soil and rhizosphere. Microbial Ecology in Health and Disease 20, 27-36.

Cappitelli, F., Sorlini, C., 2008. Microorganisms attack synthetic polymers in items representing our cultural heritage. Applied and Environmental Microbiology 74, 564-569.

Cappitelli, F., Principi, P., Pedrazzi, R., Toniolo, L., Sorlini, C., 2007a. Bacterial and fungal deterioration of the Milan Cathedral marble treated with protective synthetic resins. Science of the Total Environment 385, 172-181.

Cappitelli, F., Nosanchuk, J., Casadevall, A., Toniolo, L., Brusetti, L., Florio, S., Principi, P., Borin, S., Sorlini, C., 2007b. Synthetic consolidants attacked by melanin-producing fungi: case study of the biodeterioration of Milan (Italy) Cathedral marble treated with acrylics. Applied and Environmental Microbiology 73, 271-277.
Carretti, E., Dei, L., 2004. Physicochemical characterization of acrylic polymeric resins coating porous materials of artistic interest. Progress in Organic Coatings 49, 282-289.

Castresana, J., 2000. Selection of conserved blocks from multiple alignments for their use in phylogenetic analysis. Molecular Biology and Evolution 17, 540-552.

Cennini, C., 1437. Il libro dell'arte, 1943rd ed. Marzocco, Firenze, Italy.

Ciferri, O., 1999. Microbial degradation of paintings. Applied and Environmental Microbiology 65, 879-885.

Cole, J.R., Chai, B., Marsh, T.L., Farris, R.J., Wang, Q., Kulam, S.A., Chandra, S. McGarrell, D.M., Schmidt, T.M., Garrity, G.M., Tiedje, J.M., 2003. The Ribosomal Database Project (RDP-II): previewing a new autoaligner that allows regular updates and the new prokaryotic taxonomy. Nucleic Acids Research 31, 442-443.

El-Banna, N.M., Quddoumi, S.S., 2007. Effect of nitrogen source on the antimicrobial activity of the bacilli air flora. Annals of Clinical Microbiology and Antimicrobials 57, 669-671.

Fang, Z.G., Ouyang, Z.Y., Zheng, H., 2007. Culturable airborne bacteria in outdoor environments in Beijing, China. Microbial Ecology 54, 487-496.

Felsenstein, J., 1985. Confidence limits on phylogenies: an approach using the bootstrap. Evolution 39, 783-791.

Glass, J.E., 1997. Technology for Waterborne Coatings, ACS Symposium Series, vol. 663. American Chemical Society, Washington.

Grassi, S., Carretti, E., Pecorelli, P., Iacopini, F., Baglioni, P., Dei, L., 2007. The conservation of the Vecchietta's wall paintings in the old sacristy of Santa Maria della Scala in Siena: the use of nanotechnological cleaning agent. Journal of Cultural Heritage 8, 119-125.

Hosamani, M.K., Pattanashettar, R.S., 2003. Occurrence of unusual fatty acids in Ficus benghalensis seed oil. Industrial Crops and Products 18, 139-143.

Huang, C.H., Liang, M.F., Kam, Y.C., 2003. The fatty acid composition of oophagous tadpoles (Chirixalus eoffingeri) fed conspecific or chicken egg yolk. Comparative Biochemistry and Physiology 135, 329-336.

Jørgensen, B.B., 1990. A thiosulfate shunt in the sulfur cycle of marine sediments Science 249, 152-154.

Kiwaga, R., Hayakawa, N., Yamamoto, W., Kawanobe, C., Sano, S.A., 2005. Evaluation of mould resistance of various synthetic resins used in conservation of modern materials sites. Hozon Kagaku 44, 149-156.

Milanesi, C., Baldi, F., Vignani, R., Ciampolini, F., Faleri, C., Cresti, M., 2006a. Fungal deterioration of medieval wall fresco determined by analysing small fragments containing copper. International Biodeterioration \& Biodegradation 57, 7-13.

Milanesi, C., Baldi, F., Borin, Sara., Vignani, R., Ciampolini, F., Faleri, C., Cresti, M. 2006b. Biodeterioration of a fresco by biofilm forming bacteria. International Biodeterioration \& Biodegradation 57, 168-173.

Saarela, M., Alakomi, H.L., Siuhko, M.L., Maunuksela, L., Raaska, L., MattilaSandholm, T., 2004. Heterotrophic microorganisms in air and biofilm samples from Roman catacomb, with special emphasis on actinobacteria and fungi. International Biodeterioration \& Biodegradation 54, 27-37.

Saeed, M.A., Sabir, A.W., 2002. Irritant potential of triterpenoids from Ficus carica leaves. Fitoterapia 73, 417-420.

Silver, S., Phung, T., 2005. A bacterial view of the periodic table: genes and proteins for toxic inorganic ions. Journal of Industrial Microbiology Biotechnology 32 587-605.

Tamura, K., Dudley, J., Nei, M., Kumar, S., 2007. MEGA4: Molecular Evolutionary Genetics Analysis (MEGA) Software Version 4.0. Molecular Biology and Evololution 24, 1596-1599.

Thompson, J.D., Gibson, T.J., Plewniak, F., Jeanmougin, F., Higgins, D.G., 1997. The ClustalX windows interface: flexible strategies for multiple sequence alignment aided by quality analysis tools. Nucleic Acids Research 24, 4876-4882.

Urzì, C., Realini, M., 1998. Colour changes of Noto's calcareous sandstone as related to its colonisation by microorganisms. International Biodeterioration \& Biodegradation 42, 45-54.

Walton, D.G., Soo, P.P., Mayers, A.M., Allgor, S.J.S., Fujii, J.T., Griffith, L.G., Ankner, J.F. Kaiser, H., Johansson, J., Smith, G.D., Baker, J.G., Satija, S.K., 1997. Macromolecules 30, 6947-6956

Warscheid, T.H., Braams, J., 2000. Biodeterioration of stone: a review. International Biodeterioration \& Biodegradation 46, 343-368. 